\title{
Murinoglobulin Measurement
}

National Cancer Institute

\section{Source}

National Cancer Institute. Murinoglobulin Measurement. NCI Thesaurus. Code C127630.

The determination of the amount of murinoglobulin present in a sample. 